Ensino, Saúde e Ambiente - V11 (2), pp. 17-31, Agosto. 2018

\title{
O CONHECIMENTO DE ESTUDANTES SOBRE O HIV/AIDS E A IMPORTÂNCIA DE JOGOS E TEATRO NA RECONSTRUÇÃO DE CONCEITOS RELACIONADOS AO TEMA
}

\author{
THE KNOWLEGE OF STUDENTS ABOUT HIV/AIDS AND THE \\ IMPORTANCE OF GAMES AND THE THEATER IN THE \\ RECONSTRUCTION OF CONCEPTS RELATED TO THIS TOPIC
}

\author{
Amanda Goulart ${ }^{1}$, Debora Valim da Silva ${ }^{2}$, Andrea de Carvalho Carnevali ${ }^{3}$, Eveliny de \\ Fátima Pereira Reis ${ }^{4}$, Raphael Antônio do Prado Dias ${ }^{5}$, Jaqueline Carlos-Bender ${ }^{6}$. \\ ${ }^{1}$ Faculdade de Medicina de Ribeirão Preto (FMRP) - Universidade de São Paulo/ \\ Departamento de análises clínicas, toxicológicas e bromatológicas/ amandagoulart@usp.br \\ ${ }^{2}$ Universidade Federal de Lavras (UFLA)/Departamento de \\ Biologia/debora.valims@ hotmail.com \\ 3,4,5 Instituto Federal de Educação, Ciência e Tecnologia do Sul de Minas Gerais \\ (IFSULDEMINAS) - Câmpus Muzambinho/ andrea_carnevali@ hotmail.coM; \\ evelinyfpr@hotmail.co; raphael.a.p.dias@gmail.com \\ ${ }^{6}$ Instituto Federal de Educação, Ciência e Tecnologia de São Paulo, Campus Araraquara/ \\ Jaqueline.carlos@ifsp.edu.br.
}

\begin{abstract}
RESUMO
A Organização Mundial de Saúde relata que a grande maioria dos adolescentes inicia sua vida sexual entre 12 e 17 anos. Jovens caracterizam-se pela vulnerabilidade às Doenças Sexualmente Transmissíveis, como a Síndrome da Imunodeficiência Adquirida. Objetivamos avaliar o grau de conhecimento sobre AIDS/HIV entre adolescentes e adultos em comunidade escolar e, após a aplicação de recursos educativos, determinar a eficácia na aquisição de conhecimento sobre o assunto. $\mathrm{O}$ instrumento de coleta utilizado foram questionários que abordavam dados gerais do participante e perguntas a respeito do tema. Com base nos resultados obtidos na primeira etapa, os alunos do ensino fundamental que participaram do jogo "Zig ZAIDS", desenvolvido pela Fiocruz, e assistiram a um teatro, representando o modo de atuação do vírus HIV nas células, assim como situações do cotidiano vividas por portadores. Em seguida, um segundo questionário foi aplicado, abrangendo o conteúdo apresentado no jogo e no teatro. $\mathrm{Na}$ primeira coleta, observou-se diferenças de conhecimento entre gênero e escolaridade. A partir destes dados, observa-se a influência da escolaridade no nível de informação dos estudantes. Concluímos também que o jogo e o teatro mostraram-se efetivos para o ensino desse tema, sendo uma importante ferramenta metodológica de apoio aos professores de Biologia.
\end{abstract}

Palavras-chave: AIDS, conhecimento, HIV, jogos, teatros.

\section{ABSTRACT}

The World Health Organization reports that the great majority of teenagers start their sexual life between the ages of 12 and 17 . These youngsters are especially vulnerable to sexually transmitted diseases such as AIDS. To evaluate the level of knowledge about AIDS/ HIV among teenagers and adults in school communities and determine the efficiency in the acquisition of knowledge about the topic. The collecting tool was questionnaires, which included information about the volunteers and questions about the topic. Based on the results obtained in the first phase, junior high-school students took part in the game "Zig ZAIDS", developed by Fiocruz, and watched a play, which showed 
the way HIV virus acts on infected cells, as well as everyday life situations lived by HIV carriers. Next, a second questionnaire was applied, encompassing the content presented in the game and the play. In the first data collection, knowledge differences were observed according to gender and education level. From these data, it is possible to notice the influence of education on the students' information level. We also concluded that the game and the play proved to be effective for the teaching of this topic and an important methodological support tool for Biology teachers.

Key words: AIDS, knowledge HIV, games, theater

\section{INTRODUÇÃO}

A Síndrome da Imunodeficiência adquirida (SIDA/AIDS) é uma das mais devastadoras doenças que já existiram ${ }^{1}$. Até o final de 2016, mais de 36,7 milhões de pessoas viviam com o vírus HIV (UNAIDS, 2016), sendo que cerca de 734 mil desses casos são registrados no Brasil ${ }^{2,3}$. O portador pode ou não desenvolver a AIDS, entretanto ele tem a possibilidade de transmitir o HIV a outra pessoa, e essa, desenvolver a doença ${ }^{4}$. A síndrome é causada pelo vírus da imunodeficiência humana (HIV ou SIH), retrovírus classificado na subfamília dos Lentiviridae, que ataca o sistema Imunológico, principalmente as Células T CD4 ${ }^{+}$, alterando o DNA da célula para se replicar ${ }^{5,6}$. Após a multiplicação, a célula é rompida e a infecção continua ${ }^{4}$. Assim, a célula começa a transcrever o genoma do vírus e o organismo fica exposto a doenças oportunistas ${ }^{7}$

A AIDS surgiu entre os anos de 1977 e 1988 nos Estados Unidos, Haiti e África Central, mas só foi denominada como AIDS ou doença dos 5H (por ter sido diagnosticada em homossexuais, hemofílicos, haitianos, heroinômanos e profissionais do sexo (hookers)- o chamado "grupo de risco"), em 1982, ano em que já se conhecia os meios de transmissão ${ }^{8,9}$.

A infecção pelo vírus HIV ocorre por meio de relações sexuais sem preservativo, agulhas e seringas contaminadas (quando compartilhadas) ${ }^{9}$, pela amamentação e de mãe para filho através da transmissão vertical ${ }^{10}$.

Segundo o Programa Conjunto das Nações Unidas sobre HIV/AIDS ${ }^{11}$, a AIDS vem apresentando taxas de incidência mais elevadas nas regiões periféricas e mais pobres, entre os trabalhadores menos qualificados e pessoas com menor grau de escolarização. Entre essas populações, os jovens estão particularmente vulneráveis por estarem no início de sua vida sexual e por apresentarem, em geral, comportamentos de experimentação arriscada, como a curiosidade pelas drogas, com sentimento de invulnerabilidade. A 
maioria dos infectados se contamina pela falta de informação e pela curiosidade de infringir as "regras" 12 .

A Organização Mundial de Saúde relata que a grande maioria dos adolescentes inicia sua vida sexual cada vez mais cedo, a maioria entre 12 e 17 anos ${ }^{13}$. Esses jovens caracterizam-se pela vulnerabilidade às Doenças Sexualmente Transmissíveis (DST’s) e ao Vírus da Imunodeficiência Humana (HIV) e isso ocorre devido à liberação sexual, a facilidade dos contatos íntimos e aos estímulos vindos da comunicação que propiciam a precocidade ${ }^{14}$. Somente em 2016, cerca de 610.000 jovens entre 15 e 24 anos foram infectados, sendo cerca de 260.000 com idade entre 15 e $19^{15}$.

É importante abordar a prevenção de doenças sexualmente transmissíveis, principalmente em adolescentes, pelo fato de que estes se encontram na fase de arriscada experimentação sexual, possível uso de drogas ou falta de informações, principalmente em populações de baixa renda, condição que os torna mais suscetíveis às Doenças Sexualmente Transmissíveis ${ }^{16-18}$.

O governo, escolas e entidades atualmente procuram instruir a população sobre a AIDS. Porém, o que se observa é que, mesmo com as medidas de prevenção, de acordo com a Taxa anual de incidência de AIDS por sexo e faixa etária/100 mil habitantes, houve um aumento na taxa de infecção em jovens de 15 a 24 anos no período de 2004 a 2013 , um crescimento de 53,2\% entre aqueles com 15 a 19 anos e de $10,3 \%$ entre os de 20 a $24 .^{2}$

As campanhas na mídia são importantes, desempenhando o papel de manter a sociedade informada e, consequentemente, motivando a prevenção da doença através da busca por hábitos mais saudáveis ${ }^{19}$.

Portanto, a pesquisa visou conhecer o grau de conhecimento sobre AIDS/HIV em adolescentes e adultos em comunidade escolar, os mitos, os preconceitos envolvidos nesse tema e se os recursos aplicados influenciaram na aquisição de conhecimento sobre o assunto.

\section{MATERIAL E MÉTODOS}

\section{POPULAÇÃO DE REFERÊNCIA E AMOSTRA}

A pesquisa foi realizada em instituições de ensino situadas na cidade de Muzambinho, município do Estado de Minas Gerais, cuja população atual é de 21.026 
habitantes ${ }^{20}$. A primeira coleta foi realizada nas escolas Estadual Cesário Coimbra, Escola Estadual Professor Salatiel de Almeida, Colégio Lyceu-FAET e no Instituto Federal de Educação Ciência e Tecnologia de Minas Gerais - Campus Muzambinho; enquanto a segunda coleta analisou dados das duas primeiras escolas supracitadas, avaliando as questões com maior porcentagem de erro encontrada no primeiro questionário. Os alunos participantes cursavam diferentes níveis de ensino, compreendendo desde o ensino fundamental até o superior.

\section{INSTRUMENTO}

$\mathrm{O}$ instrumento de coleta consistiu em dois questionários, onde o primeiro questionário era composto por onze questões fechadas com respostas sim, não e não sei, além de questões acerca de dados pessoais, como sexo, idade e série cursada. O segundo questionário continha quatro questões e foi aplicado logo após a apresentação dos jogos e teatros. Todo o estudo foi feito de forma a proteger a identidade dos indivíduos, que eram voluntários e anônimos. O projeto foi submetido ao comitê de ética em pesquisa com seres humanos da Universidade de Ribeirão Preto, onde foi avaliado e aprovado em 19 de dezembro de 2011 e registrado sobre o ComEt 85/2011. Questionários pilotos foram aplicados em dez indivíduos de diferentes graus de escolaridade, para a adequação da linguagem encontrada nas questões e possíveis erros de interpretação.

\section{JOGOS E TEATROS}

Os jogos e teatros foram embasados em dados colhidos e analisados durante a primeira aplicação do questionário e tiveram como tema os principais erros encontrados nos questionários, além da esquematização da ação do vírus no organismo. Os alunos se dividiram em grupos de até cinco pessoas para jogar o Zig ZAIDS, jogo desenvolvido pelo departamento de Biologia do Instituto Oswaldo Cruz (Fiocruz), que consiste em um jogo de tabuleiro e cartões com questões relacionadas aos conhecimentos sobre doenças sexualmente transmissíveis (DST), principalmente a AIDS. O jogo pode ser encontrado também em versão digital. Os teatros foram direcionados e modelados de acordo com a faixa etária dos alunos e mostraram a ação do vírus nas células $\mathrm{T}$, as formas de transmissão e não transmissão da doença e visavam corrigir possíveis conceitos errôneos 
sobre o tema HIV/AIDS.

\section{COLETA DE DADOS}

Para a análise estatística que visou avaliar a influência dos jogos e teatros na aquisição de conhecimento sobre HIV/AIDS, foi utilizado um questionário, que continha quatro questões. As primeiras três questões incluiam três opções de respostas: sim, não e não sei. A quarta questão tratava do sistema que pertencia à célula infectada pelo vírus HIV e suas opções eram: sistema auditivo, sistema respiratório e sistema imunológico.

\section{ANÁLISE ESTATÍSTICA}

A análise estatística dos dados foi realizada seguindo um critério de agrupamento de resposta, sendo as possíveis respostas agrupadas em duas categorias: "informado" (inf) e "não informado" (n-inf). No primeiro questionário, a resposta "sim" foi considerada inf para as questões: (3) Se eu tiver relação sexual sem proteção, apenas uma vez, com uma pessoa com AIDS, corro o risco de me contaminar? (8) Se eu for picado por uma seringa, usada por uma pessoa com AIDS, posso me contaminar? (10) Se eu receber sangue de uma pessoa com AIDS, posso me contaminar? As demais respostas (não e não sei) foram consideradas $n$-inf para essas questões. A resposta "não" foi considerada inf para as questões: (1) Se uma pessoa com AIDS espirra perto de mim, posso me contaminar? (2) Se utilizar um copo que acaba de ser utilizado por uma pessoa com AIDS, corro o risco de me contaminar? (4) Se eu conviver dia-a-dia com uma pessoa com AIDS, posso me contaminar? (5) Se eu utilizar o mesmo sanitário que uma pessoa com AIDS, posso me contaminar? (6) Se eu utilizar os mesmos talheres que uma pessoa com AIDS, corro o risco de me contaminar? (7) Se eu beijar uma pessoa com AIDS há risco de contaminação? (9) Se eu doar sangue corro o risco de me contaminar com o vírus da AIDS? (11) Se eu entrar em uma piscina onde está uma pessoa com AIDS, posso me contaminar? As demais respostas (sim e não sei) foram consideradas $n$-inf para essas questões. No segundo questionário, a resposta "sim" foi considerada inf para a questão (1) Uma pessoa portadora do vírus HIV pode conviver normalmente com outras pessoas? As demais respostas (não e não sei) foram consideradas $n$-inf para a questão. A resposta "não" foi considerada inf para as questões: (2) O vírus HIV pode ser transmitido por talheres e copos? (3) O vírus pode ser transmitido quando doamos sangue em unidades 
de saúde? As demais respostas ( $\operatorname{sim}$ e não sei) foram consideradas $n$-inf para as questões. A resposta "Sistema Imunológico" foi considerada inf para a questão: (4) O vírus HIV invade qual sistema do nosso organismo? As demais respostas (Sistema Respiratório e Sistema Auditivo) foram consideradas $n$-inf para a questão. O programa utilizado para a análise estatística foi programa SISVAR, e a análise que foi utilizada foi o teste de hipótese de proporções, onde os resultados estatisticamente significativos obtiveram $\mathrm{P}$ valor menor que 0,05 .

\section{RESULTADOS}

No desenvolvimento do trabalho, nenhuma escola se opôs em receber os entrevistadores, dada à grande importância de relatar este assunto em sala de aula. Em apenas uma houve no início oposição por parte da direção, já que a aplicação do questionário poderia interferir no andamento das aulas.

O número de participantes da pesquisa de alunos menores de 18 (dezoito) anos foi menor do que o previsto, por terem que apresentar termo de consentimento assinado pelos responsáveis (exigência do comitê de ética), onde muitos alunos não apresentaram aos pais e muitos pais não quiseram que os filhos participassem da pesquisa. No entanto, conseguimos um número significativo de participantes maiores de idade, totalizando 756 participantes. No primeiro questionário, obtivemos os seguintes dados:

$\mathrm{Na}$ comparação por sexo, as questões que apresentaram diferença $(\mathrm{p}<0,05)$ foram à transmissão ou não do vírus HIV pelo uso de talheres e pelo beijo, onde os menos informados eram os homens. Em relação à transmissão ou não do vírus pelo uso de assento sanitário, a proporção de não informados é maior entre as mulheres (Figura 1). 
Figura 01 - Comparação entre informados masculinos e femininos. As respostas consideradas inf foram agrupadas em feminino e masculino para as questões: (1) Se uma pessoa com AIDS espirra perto de mim, posso me contaminar? (2) Se utilizar um copo que acaba de ser usado por uma pessoa com AIDS, corro o risco de me contaminar? (3) Se utilizar um copo que acaba de ser usado por uma pessoa com AIDS, corro o risco de me contaminar? (4) Se eu conviver dia-a-dia com uma pessoa com AIDS, posso me contaminar? (5) Se eu utilizar o mesmo sanitário que uma pessoa com AIDS, posso me contaminar? (6) Se eu utilizar os mesmos talheres que uma pessoa com aids, corro o risco de me contaminar? (7) Se eu beijar uma pessoa com AIDS, há risco de contaminação? (8) Se eu beijar uma pessoa com AIDS, há risco de contaminação? (9) Se eu doar sangue corro o risco de me contaminar com o vírus da AIDS? (10) Se eu receber sangue de uma pessoa com AIDS, posso me contaminar? (11) Se eu entrar em uma piscina onde está uma pessoa com AIDS, posso me contaminar?

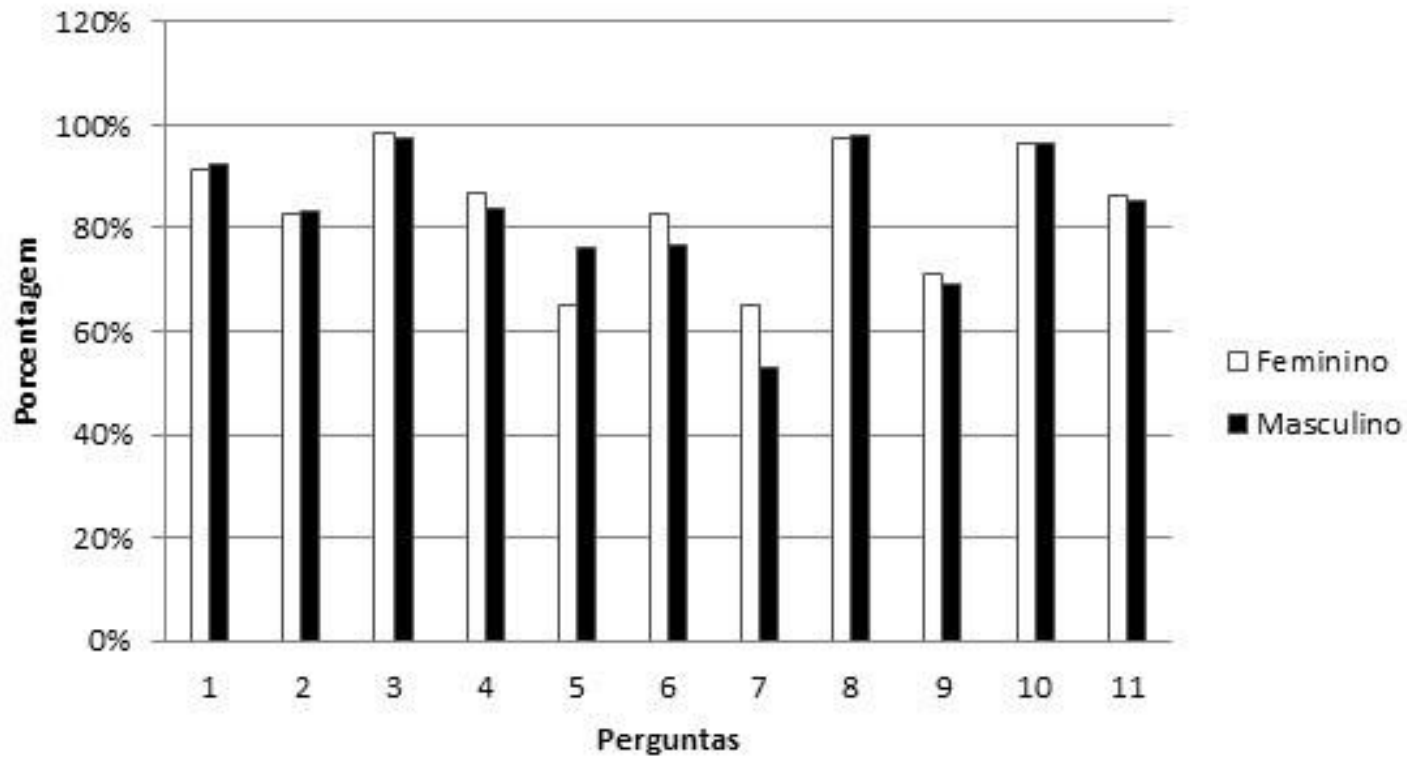

Fonte: Goulart et al, 2018.

Comparando-se as escolas públicas e privadas, observamos ausência de diferenças, mostrando uma homogeneidade do ensino do tema na região (Figuras 2 e 3 ). 
Figura 02 - Informados entre alunos de ensino fundamental de escolas públicas e particulares do município de Muzambinho - MG. As respostas consideradas inf foram agrupadas em ensino fundamental de escolas públicas e particulares para as questões já descritas na figura 1.

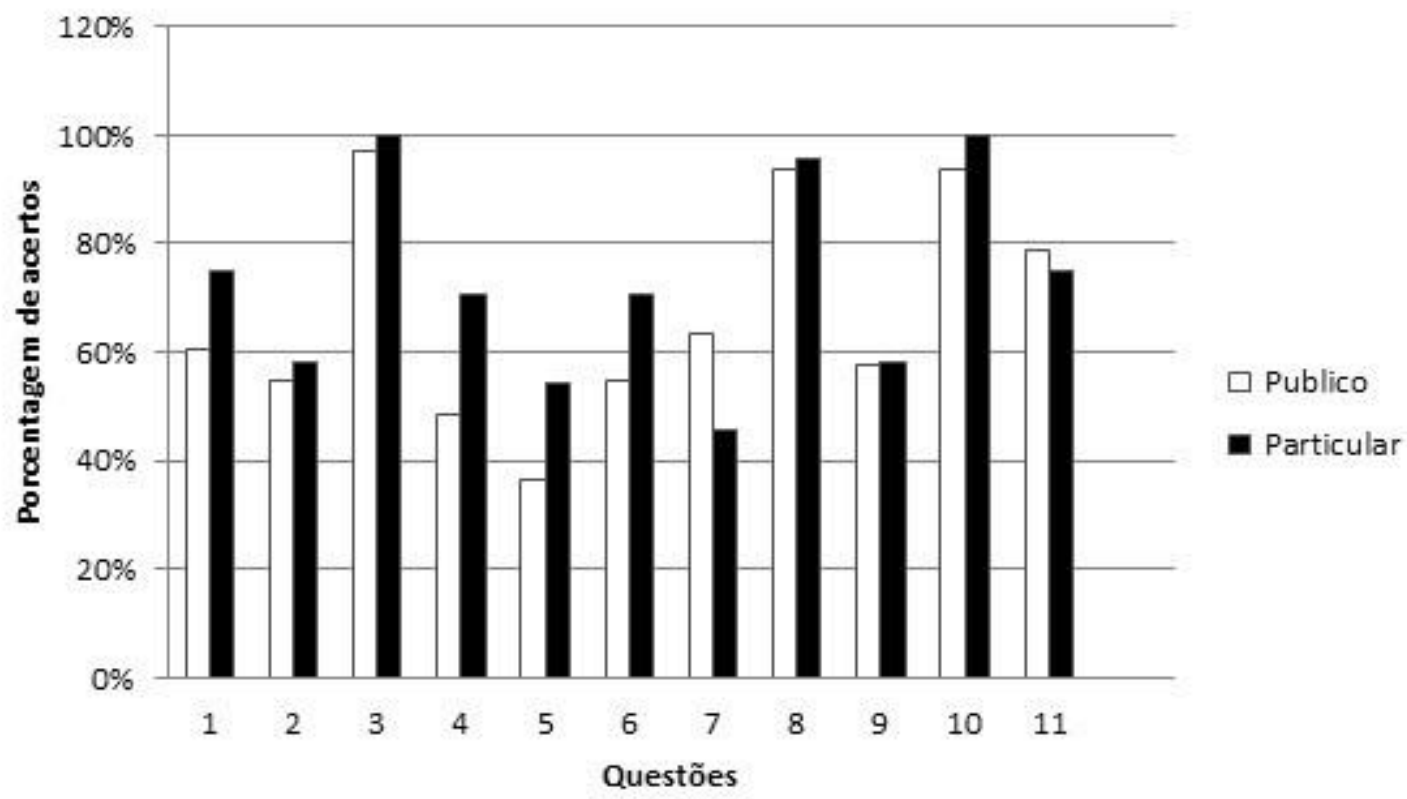

Fonte: Goulart et al, 2018.

Figura 03 - Comparação entre informados de alunos de ensino médio de escolas públicas e particulares do município de Muzambinho - MG. Legenda: As respostas consideradas inf foram agrupadas em ensino médio de escolas públicas e particulares para as questões já descritas na figura 1.

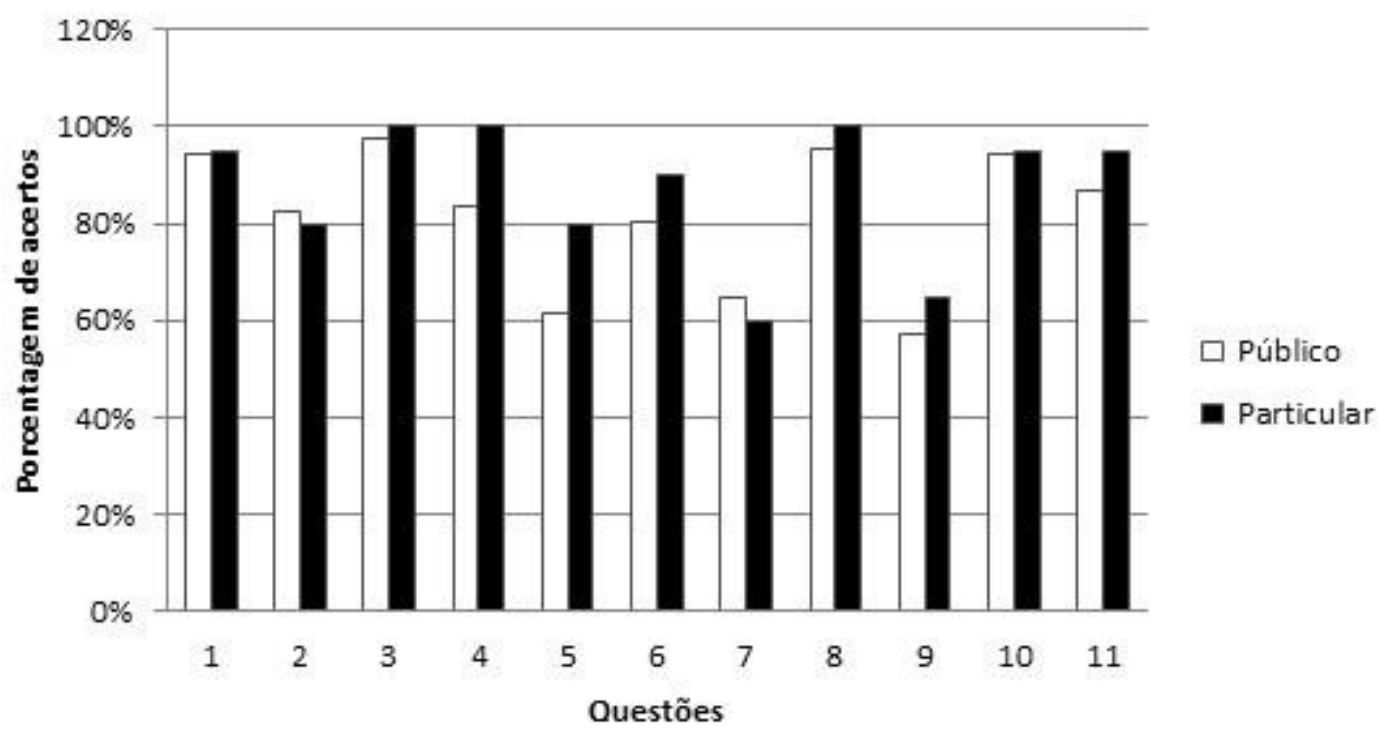

Fonte: Goulart et al, 2018.

Comparando Ensino Médio e Ensino Fundamental, as questões que apresentaram diferença foram à transmissão do vírus por espirro, uso de copo, 
convivência diária, uso de vaso sanitário e talheres. (Figura 4). Dados semelhantes foram encontrados quando se comparou o Fundamental com o Técnico ou com o Superior, onde o número de informados no ensino Fundamental foi menor (Figura 4). Comparando Ensino Médio com o Ensino Técnico ou com o Superior, as questões que apresentaram diferenças foram à transmissão pelo uso de vaso sanitário e pela doação de sangue, onde os não informados cursavam o ensino Médio. Não houve diferença significativa entre o Técnico e Superior (Figura 4).

Figura 04 - Porcentagem informada de alunos de ensino fundamental, médio, técnico e superior de escolas públicas e particulares do município de Muzambinho - MG. As respostas consideradas inf foram agrupadas em níveis de escolaridade do total de participantes.

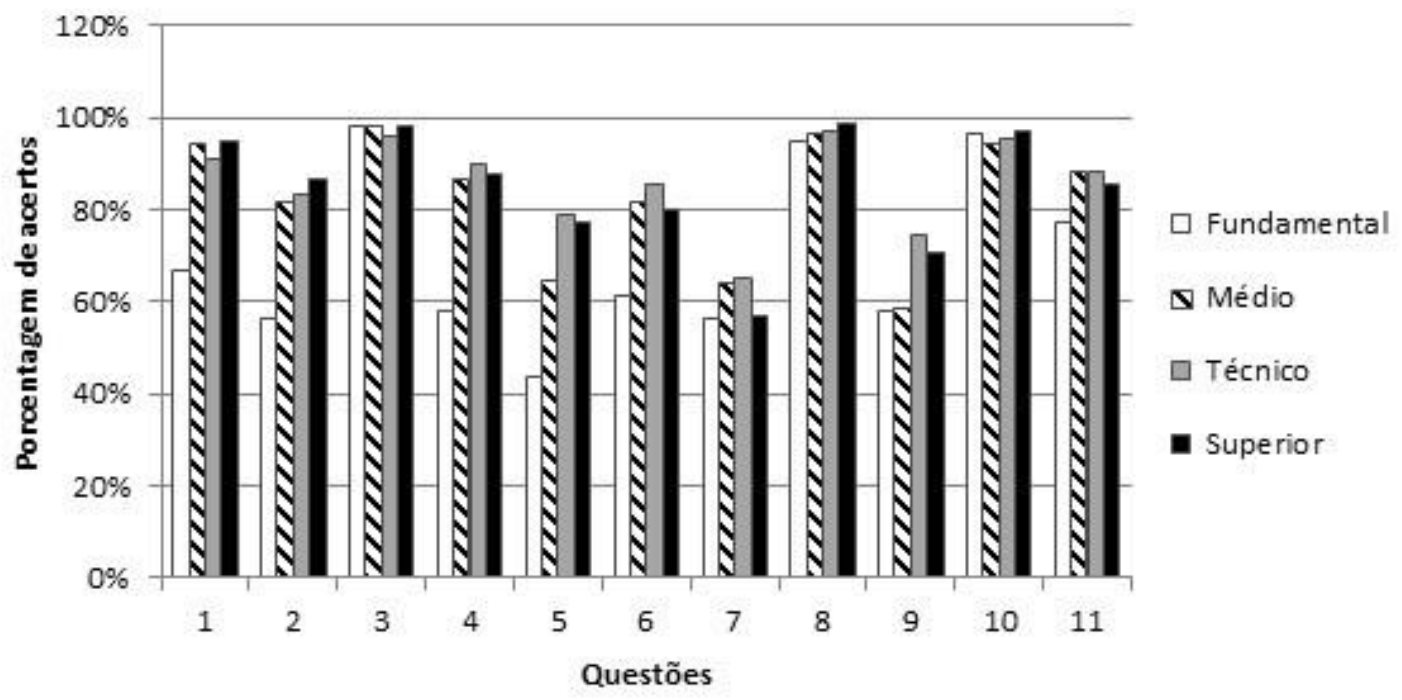

Fonte: Goulart et al, 2018.

Na segunda etapa da pesquisa, após os jogos, teatros, aplicação dos questionários e a análise estatística, observaram-se as porcentagens de erros e acertos de acordo com o ano/série dos alunos. Em alunos do $9^{\circ}$ ano (14 à 16 anos), na questão (1), 93\% dos participantes se mostraram informados. Na questão (2), 94\% dos alunos se mostraram informados. Na questão (3), 50\% dos alunos se mostraram informados e na questão (4), 97\% dos participantes de $9^{\circ}$ ano se mostraram informados (Figura 05). Os participantes de $7^{\circ}$ ano (12 e 15 anos), na questão (1), 87\% dos participantes se mostraram informados, questão (2), 98\% dos alunos se mostraram informados, questão (3), 84\% dos alunos se mostraram informados e questão (4), $90 \%$ dos participantes de $7^{\circ}$ ano se mostraram informados (Figura 5). Entre os participantes de $6^{\circ}$ ano (11 e 13 anos), na questão (1), 
$84 \%$ dos participantes se mostraram informados, na questão (2), 93\% dos alunos se mostraram informados, na questão (3), 77\% dos alunos se mostraram informados, na questão (4), 96\% dos participantes se mostraram informados (Figura 05).

Figura 05 - Porcentagem informada entre alunos de $9^{\circ}, 7^{\circ}$ e sexto ano do ensino fundamental. As respostas consideradas inf foram agrupadas em feminino e masculino para as questões: (1) "Uma pessoa portadora do vírus HIV pode conviver normalmente com outras pessoas?", (2) “O vírus HIV pode ser transmitido por talheres e copos?", (3) "O vírus pode ser transmitido quando doamos sangue em unidades de saúde?" e (4) “O vírus HIV invade qual sistema do nosso organismo?”.

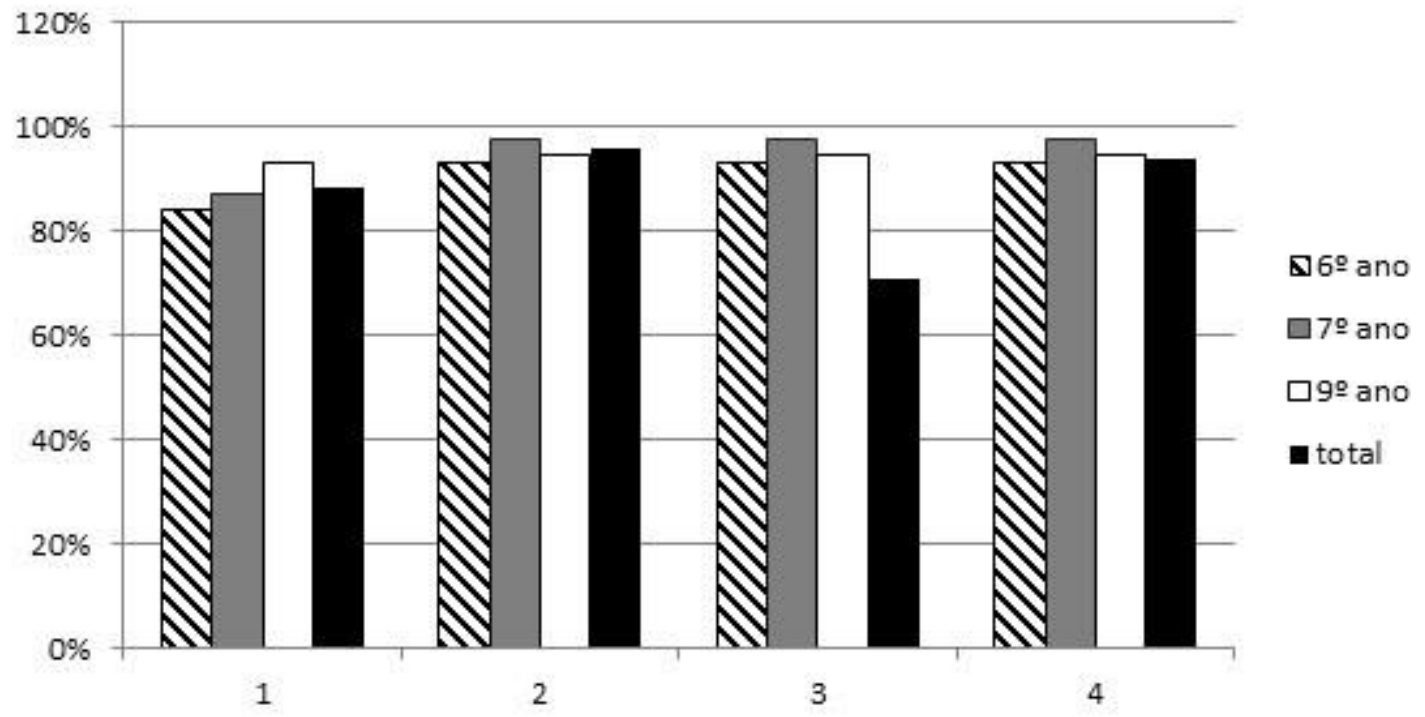

Fonte: Goulart et al, 2018.

Do total de participantes, alunos de $6^{\circ}, 7^{\circ}$ e $9^{\circ}$ anos, que tinham idade entre $11 \mathrm{e}$ 16 anos, a porcentagem dos participantes que se mostraram informados foram: na questão (1), 89\%; na questão (2), 96\%; na questão (3), 71\% e na questão (4), 94\% (Figura 06). 
Ensino, Saúde e Ambiente - V11 (2), pp. 17-31, Agosto. 2018

Figura 06 - Porcentagem informada entre o total de alunos participantes. As respostas consideradas inf para as questões já descritas na figura 5.

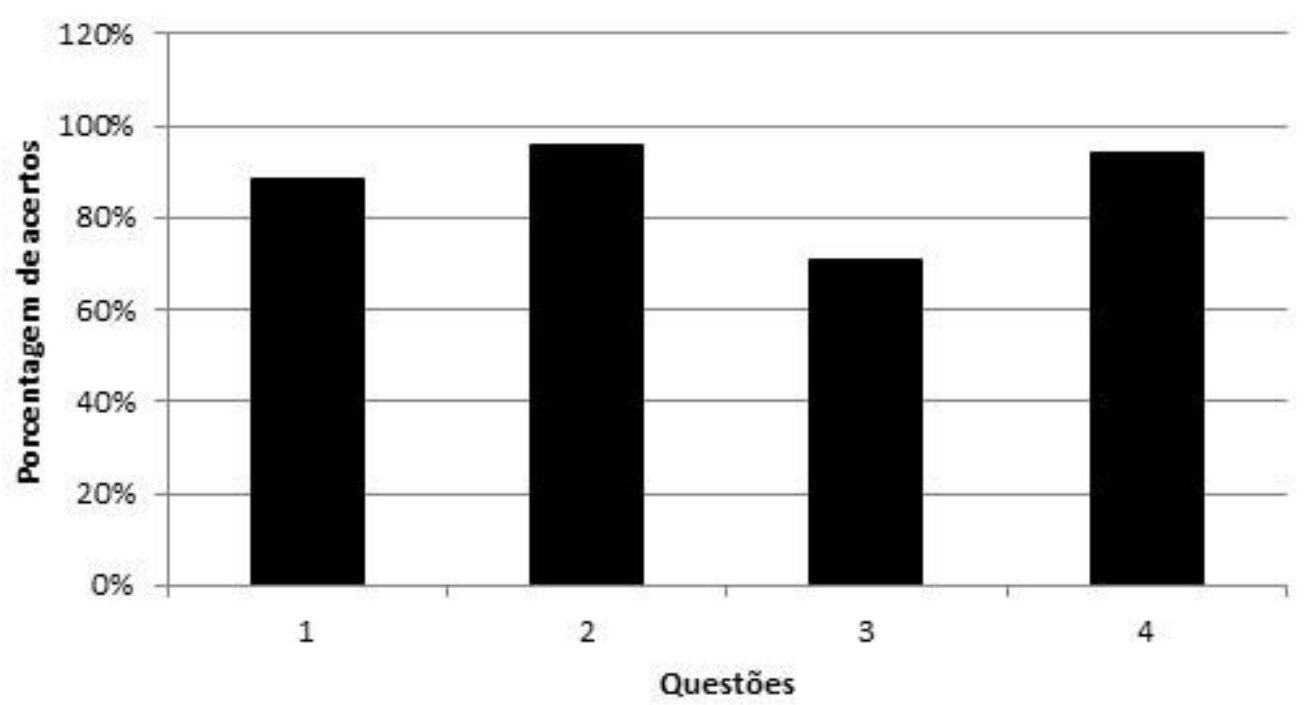

Fonte: Goulart et al, 2018.

\section{DISCUSSÃO}

A partir dos dados obtidos nos questionários, nota-se que a maioria dos estudantes têm conhecimento sobre o assunto, principalmente quando este foi abordado pela mídia em campanhas.

Um importante dado observado foi a baixa porcentagem de respostas corretas entre as participantes do sexo feminino (65\%), quando questionadas sobre a transmissão do vírus HIV pelo vaso sanitário. O uso do sanitário pelas mulheres ocorre de maneira diferente dos homens, uma vez que o contato com o assento pode ocorrer mais facilmente durante o uso do mesmo por elas. Alencar et. al obteve dados semelhantes quando questionou participantes que cursaram até ensino fundamental (56\% de acertos) e até ensino médio $(62,7 \% \text { de acertos })^{11}$.

A falta de diferença estatisticamente significativa entre os níveis de conhecimento dos alunos cursando o mesmo nível de escolaridade, em ensino privado ou público, revela a eficácia dos meios de informação relacionada ao assunto para alunos de diferentes classes sociais.

A questão (3) do segundo questionário "O vírus pode ser transmitido quando doamos sangue em unidades de saúde?", aplicada em alunos cursando $9^{\circ}$ ano, quando 
apenas $50 \%$ dos participantes assinalaram a alternativa correta, e lembrando que em todos os outros níveis houve porcentagem de acerto maior que $70 \%$. Esse dado sugere que muitas pessoas têm receio em doar sangue devido a acreditarem que há a possibilidade de contaminação durante o processo. Fernandes, obteve $56 \%$ de acertos na questão relativa a doação de sangue e transmissão do HIV em pessoas com idade média de 29 $\operatorname{anos}^{21}$. Camargo também pesquisou o assunto, e obteve uma porcentagem de erro de $34,5 \%$ em adolescentes ${ }^{22}$. Coelho também obteve um alto índice de concepções errôneas quando o assunto é doação de sangue, $35,8 \%$, sendo esses índices maiores entre os jovens 23.

Pereira realizou uma pesquisa que também se tratava de transmissão e não transmissão do HIV, em um grupo de idosos ${ }^{14}$. Em seu questionário, obteve $62 \%$ de acertos na questão sobre transmissão por talheres e copos. Pereira também questionou sobre convivência. 75,8\% dos entrevistados responderam corretamente a questão sobre transmissão por beijo no rosto, abraço e aperto de mão ${ }^{14}$. $75 \%$ dos idosos participantes também responderam corretamente quando questionados sobre a não transmissão quando sentados ao lado de um soropositivo.

Lima et. al em uma pesquisa realizada em Viçosa, MG, obteve 63,9\% de respostas corretas em indivíduos que ainda cursavam ensino fundamental, quando questionaram sobre a não transmissão do vírus HIV quando havia compartilhamento de copos ${ }^{11}$. Quanto ao questionamento sobre a não transmissão do HIV quando existe a doação de sangue, os mesmos autores obtiveram a mesma porcentagem $(63,9 \%)$ de acertos.

Os dados obtidos com a pesquisa demonstram a importância dos diversos meios de comunicação na conscientização da população, principalmente dos jovens, quanto às formas de transmissão, os mitos e preconceitos que ainda envolvem este tema. É necessária também a quebra de tabus impostos pelas famílias ao abordarem estes assuntos.

De acordo com o Perfil Epidemiológico de Santa Catarina, ao longo dos anos, o número de infectados pelo vírus HIV vem aumentando, principalmente entre as pessoas de menos escolaridade, o que reforça a necessidade de um trabalho de educação e orientação contínua, podendo os educadores aproveitar da curiosidade que o tema HIV desperta nos adolescentes, para abordar, de modo complexo, todas as formas de 
transmissão e fases do desenvolvimento do vírus, contribuindo efetivamente na prevenção da doença ${ }^{24}$.

\section{CONCLUSÃO}

O Brasil é reconhecido como o país onde as políticas de prevenção ao HIV/AIDS são das mais eficientes ${ }^{25}$. O Ministério da Saúde realiza campanhas através da mídia, cartazes e panfletos para informar a população sobre a prevenção do HIV/AIDS e também distribui, de forma gratuita, preservativos masculinos e femininos nos postos de saúde ${ }^{26}$. Contudo, o índice de infectados pelo vírus ainda é muito grande. Essas campanhas de distribuição de preservativos são precárias e não atingem a totalidade da população ${ }^{24}$. Além das secretarias de saúde, as escolas também têm um importante papel quando se trata da divulgação de temas relacionados à doenças sexualmente transmissíveis, sendo hoje em dia o local onde o jovem permanece a maior parte do tempo. Ademais, foi constatado que a utilização de jogos e teatros nas escolas diminuiu significativamente os erros conceituais e preconceitos observados na primeira etapa da pesquisa. Na questão da prevenção, a população deve ser orientada e educada continuamente, de modo que o conhecimento faça parte da cultura e do comportamento diário, sendo necessária a participação de serviços de saúde, das escolas, da mídia e a da família, para que todas essas campanhas se tornem realmente eficazes e possa reduzir o número de casos por infecção desse grande mal que é o HIV.

\section{REFERÊNCIAS}

1. KERR, T.; KENDALL, L. R. F. S., C. \& MOTA, R. M. S. Universidade Federal do Ceará. Faculdade de Medicina, Fisioterapia \& amp; saúde funcional. Fisioterapia \& Saúde Funcional. v. 3, 2014.

2. Aids/HIV no Mercosul | Departamento de Vigilância, Prevenção e Controle das IST, do HIV/Aids das Hepatites Virais. 2015.

3. WHO. Estatísticas - UNAIDS Brasil. 2016. Available at: http://unaids.org.br/estatisticas/. Accessed: 6th September 2017

4. MINISTARIO DA SAUDE. O que é HIV | Departamento de Vigilância, Prevenção e Controle das IST, do HIV/Aids das Hepatites Virais. 2017. Available at: http://www.aids.gov.br/pt-br/publico-geral/o-que-e-hiv. Accessed: 6th September 2017. 5. FAUCI, A. S., SCHNITTMAN, S. M., POLI, G., KOENIG, S. \& PANTALEO, G. Immunopathogenic Mechanisms in Human Immunodeficiency Virus (HIV) Infection. 
Ann. Intern. Med. v.114, p. 678, 1991.

6. PORTAL DA SAÚDE. O QUE É HIV? 2014. Available at: http://portalsaude.saude.gov.br/index.php/links-de-interesse/286-aids/9053-o-que-e-hiv. Accessed: 6th September 2017.

7. HOLGATE, S. T. Mechanisms of asthma and implications for its prevention and treatment: A personal journey. Allergy, Asthma and Immunology Research 2013. doi:10.4168/aair.2013.5.6.343.

8. GUIMARÄES, M. D. C. Estudo temporal das doenças associadas à AIDS no Brasil, 1980-1999. 2000. doi:268482.

9. PAIVA, V. et al. Youths and Adolescents in the Age of AIDS: Reflections About a Decade of Work in HIV Prevention. Psicol. USP. v. 13, p. 55 78, 2002.

10. FERREIRA, M. P. \& Fundação Seade São Paulo, B. Knowledge and risk perception on HIV/AIDS by Brazilian population, 1998 and 2005. Rev. Saúde Pública. v. 42, p. 65 $71,2008$.

11. DE ALENCAR, E.-C., BRANDÃO, J, ANTONINI, C. \& DE LIMA, P. Transmissão vertical e HIV. Ciência Consciência. v. 1, 2008. doi:http://www.revista.ulbrajp.edu.br/seer/inicia/ojs/viewarticle.php?id=1609

12. WHO. WHO | The UNAIDS/WHO Working Group on global HIV/AIDS and STI Surveillance. WHO .2011.

doi:/entity/hiv/strategic/surveillance/workinggroup/en/index.html

13. WHO | World Health Organization. WHO (2014). doi:/en/index.html

14. BRÊTAS, J. R. da S. et al. Knowledge of STD/AIDS among adolescent students. Rev. esc. enferm. USP. v.43, p.551 557, 2009.

15. Adolescents and Young People - UNICEF DATA. 2017. Available at: https://data.unicef.org/topic/hivaids/adolescents-young-people/. Accessed: 11th September 2017.

16. MARTINI, J. G. \& BANDEIRA ADA, S. [Knowledge and practice of adolescents in the prevention of sexually transmitted diseases]. Rev Bras Enferm. v. 56, p.160 163, 2003.

17. CAMARGO, B. V., CATARINA, U. F. DE S., BARBARÁ, A. \& CATARINA, U. F. de S. Effects of informative leaflets about AIDS on adolescents. Psic. Teor. e Pesq. v. 20, p. 279 287, 2004.

18. TAQUETTE, S. R. et al. Sexually transmitted diseases and gender: a cross-sectional study with adolescents in Rio de Janeiro. Cad. Saúde Pública. v. 20, p. 282 290, 2004.

19. JABUR, P. de A. C. \& NASCIMENTO, S. L. do. O impacto das campanhas de DST/AIDS no comportamento sexual dos adolescentes. 2012. doi:http://bdm.unb.br/handle/10483/4432.

20. IBGE: Instituto Brasileiro de Geografia e Estatística. 2017. Available at: http://www.ibge.gov.br/home/. Accessed: 11th September 2017.

21. FERNANDES, J. C. L. \& de Saúde da Associação dos Moradores e Amigos do Bairro Barcellos Rio de Janeiro, B. Trends in HIV/Aids-related knowledge, attitudes, and practices in a Rio de Janeiro slum population. Cad. Saúde Pública. v. 14, p. 575 
Ensino, Saúde e Ambiente - V11 (2), pp. 17-31, Agosto. 2018

$581,1998$.

22.CAMARGO, B. V; B., BOTELHO, L. J. AIDS, sexuality and attitude of adolescents about protection against HIV. Rev. Saúde Pública. v. 41, p. 61 68, 2007.

23. COELHO, R. F. de S., SOUTO, T. G., SOARES, L. R., LACERDA, L. C. M. \& MATÃO, M. E. L. Knowledge and beliefs about sexually transmitted disease and HIV/AIDS among adolescents and young people of state public schools of the west region of Goiania city, Brazil. 2011. doi:592375.

24. TCHAICKA, V. M. V. PREVENÇÃO DA INFECÇÃO PELO VÍRUS HIV ENTRE ADOLESCENTES: Prevenir é o melhor remédio. 2013.

25. Estatísticas - UNAIDS Brasil. Available at: http://unaids.org.br/estatisticas/. Accessed: 6th September 2017.

26. BARROS, N. B., GUIMARÃES, C. M. \& BORGES, O. de S. Políticas de Saúde e Prevenção ao Hiv/Aids no Brasil 1982-2012. Estudos. v. 39, p. 537 546, 2012. 